\title{
Téoros
}

Revue de recherche en tourisme

\section{Le tourisme d'affaires : un phénomène à mieux connaître}

\section{Normand Cazelais}

Volume 15, numéro 3, automne 1996

Le tourisme d'affaires

URI : https://id.erudit.org/iderudit/1075057ar

DOI : https://doi.org/10.7202/1075057ar

Aller au sommaire du numéro

Éditeur(s)

Université du Québec à Montréal

ISSN

0712-8657 (imprimé)

1923-2705 (numérique)

Découvrir la revue

Citer ce document

Cazelais, N. (1996). Le tourisme d'affaires : un phénomène à mieux connaître. Téoros, 15(3), 3-3. https://doi.org/10.7202/1075057ar d'utilisation que vous pouvez consulter en ligne.

https://apropos.erudit.org/fr/usagers/politique-dutilisation/ 


\section{LE TOURISME D'AFFAIRES: UN PHÉNOMĖNE À MIEUX CONNAÎTRE}

\author{
Normand Cazelais, \\ coordonateur du numéro
}

Malgré son importance, le tourisme d'affaires est peu connu. C'est pourquoi. d'entrée de jeu en ce numéro, un texte s'imposait, celai d'en cerner les divers tenants et aboutissants, tant au plan des concepts qu'à celui des defmitions. Je vous live donc mes réflexions à ce propos.

Jean Stafford, Charles Bélanger et Brigite Maheu nous expliguen, pour leur part, qu'il n'est guère aise de connaître avec précision ce phénomène, du moins en termes quantitanifs, en raison du manque de donnes fiables foumies par les Erats on les organismes internationaux all est pratiquement impossible, observent-ils, d'avoir une image chronologique claire de (son) évolution au cours des vingt dernieres années. IIs livent néanmoins we analyse générale de la simation dans onze pays du monde et plas particulièrement au Québec et au Canada.

Jean Pelletier ensuite, s'intéresse au blues du businessman (et tout autant de la businesswoman..) qui, avec des millions de leurs pareils, doivent fréquenter l'un des quelque 6000 aéroports du monde. Cet umivers est en ébullition: les voyageurs d'affaires, toujows plus nombreux, ont des besoins sans cesse plus sophistiqués, les avions changent à la vitesse grand V, tout comme les lieux ou ils se posent ef d'où ils décollent, "Anuullement, note-il, se brassent des centaines de milliards dans l'aéronautique à l'échelle mondiale. (...) Sky is the limit. (...) Bienvenue au XXIe siècle! Le futur est déjà arrivé.

Ce tourisme d'affaires, relèvent Pierre Bellerase et Bethe Beauregand, représente "I0 000 emplois pour Montéals. Son développement, à leurs yeux, est aprioritaire puisque les touristes d'affaires, participant à des congrès, colloques, expositions et autres réunions d'affaires, y engendrent des retombees de 440 millions de dollars, soit $35 \%$ des dépenses touristiques: ace montant est d'autant plus impressionnant que les visiteurs d'affaires ne représentent que $19,7 \%$ du total des touristes venus à Montréal.

Dans ce contexte, demande Guy $R$. Morin, "que résenve l'avenir de l'industrie des expositions à Montréals? De plus en plus, les grandes expositions annuelles ou biennales recherchent les "grandes infrastructures intégrées.. Le choix des villes de congrès ou d'exposition, selon lui, favorisera des destinations thematiques (et), au Canada, la position de Montréal risque de se détérioner, derrière lavance de Toronto et la croissance de Vancouver. D'ò̀ La nécessité à cet effer "d'analyser froidement nos forces et faiblessesw.

Présentés comme des bilans d'intervention, d'autres textes étudient, dans leurs specificites, plusieurs manifestations du tourisme d'affaires: "Montréal... Genève du XXIe siècle? p par Sylvie Fafard (qui decorique notamment le processus de sollicitation d'un congrès), "L'organisation d'un congrèss (qui demande une planification rigoureuse) par Sophie Choquette, ainsi que "Tourisme d'affaires et libre-échange et wVyages de motivation et opportunites d'affames. que je signe.

Deux portraits, puisés à la réalité de l'espace, completent ce rapide survol: $\&$ La santé économique d'whe région (plus particulierement celle de Sherbrooke) par Lynda Généreux et ale tourisme d'affaires en He-de-Frances (région qui fait couronne autour de Paris, premiere ville de congrès au monde).

Enfin, précedant une bibliographie portant sur les congrès et foires préparée par Valerie Théberge, Marc Laplante, soumet à notre attention quelques aéléments d'analyse socio-culturelles qui font contrepoint à cette vision densemble: "II ne faut poss être sorcies écrit-il, pour entrevoir qu'avec le lemps c'est le voyage d'agrément (...) qui va s'accroitre.s.

La connaissance du tourisme d'affaires $n$ 'a pas fini d'alimenter les discussions et interrogations.. 